\section{REEF MORPHOLOGY}

Atlas of the Great Barrier Reef

By W. G. H. Maxwell. Pp. 258. (Elsevier: Amsterdam, London and New York, 1968.) 2158.

Professor Maxwell's book appears forty ycars after the Great Barrier Reef Expedition of 1928-29 laid the foundations of our knowledge of the Australian reefs with its meticulous surveys of Low Isles and Three Isles, north of Cairns, and ils reconnaissance of other areas. Despite the continuing activity of the Great Barrier Reef Committee and of a few other investigators, no studies comparable with those of the Great Barrier Reef Expedition have been undertaken until very recently, so that large areas of the world's greatest reef are still among the least known scientifically.

This handsome and expensive book is less an atlas than a discussion of the geology, geomorphology, environments and sediments of the Barrier Reefs, illustrated with maps, diagrams and photographs. In treatment it is, perhaps inevitably, uneven, both geographically and topically. Maxwell's own experienec, and that of his students, has been concentrated around the Capricorn complex at the southern end of the $1,600 \mathrm{~km}$ long reef province; and very little has been done at all on the reefs north of Cooktown at $15^{\circ} 30^{\prime} \mathrm{S}$. Maxwell's own work has been on reef and shelf sediments in the southern area, and his long chapter on sediments concentrates on facies and constituents south of $20^{\circ} 30^{\prime} \mathrm{S}$. Much information is summarized in a series of fold-outs containing a series of five maps of sectors of the reef, and it is unfortunate for the reader that these cannot all be on the same scale and orientation.

The longost sections of the book, and its original contributions, are those dealing with reef and submarine morphology and sedimentary patterns. Evidence is presented in echograms and simplified sections for the existence of the following submarine features (depths converted to metres, rounded to $0.5 \mathrm{~m}$, originals in fathoms): scarp and ledge at 5.5-7 $\mathrm{m}$ depth, terrace and ridge at $18-22 \mathrm{~m}$, plain and ridge at $29 \mathrm{~m}$, surface and scarp at $37-44 \mathrm{~m}$, surface and ridge at $58.5 \mathrm{~m}$, ridge at $66 \mathrm{~m}$, terrace at $88 \mathrm{~m}$, and ridge at $102.5 \mathrm{~m}$. Three main "pre-Recent" sea levels are identified (Fig. 22) at $-29 \cdot 5,-40$ and $-58.5 \mathrm{~m}$, and drainage lines on the sholf during Pleistocene emergence are reconstructed on largely bathymetric grounds for the whole reef area. A systematic chronology of reef development is presented in Fig. 32 in terms of successive sea-levels at $-146.5,-88$, $-66,-29 \cdot 5,-58 \cdot 5,-36 \cdot 5$ and $+3 \mathrm{~m}$.

These reconstructions are not inherently improbable, but they have not been established in the literature and they are not well established in this book. It is surprising that no attempt is made to provide an absolute chronology for these changes, nor to consider the evidence for fluctuations on the Queensland coast to which Steers drew attention, nor to link the scheme through to recent detailed work on sea-level changes in New South Wales and South Australia. It is puzzling that no use is made of evidence from deep bores at Heron Island, Michaelmas Cay and Wreck Island, for palaeontological and diagenetic data from Pacific atoll cores have been mainly responsible for establishing the outlines of Quaternary sea-level movement in the Pacific basin. Future workers on the Great Barrier Reef will inevitably be concerned with testing Maxwell's interpretation, but they are entitled to be given more detailed evidence than is presented here, not at the scale of the entire reef but of manageable sectors of it.

Maxwell's treatment of reef morphology is based largely on air photographs and aerial mapping, and I believe that the most valuable feature of the book is the series of fairly small-scale $(1: 50,000-1: 75,000)$ vertical photographs showing the variety and complexity of reef forms. This is a subject almost completely unexplored in the literature, though the forms illustrated are common in Caribbcan and Indian Ocean reefs as well as in the Pacific. New, not always euphonious or illuminating terms are introduced for these reef forms: wall, cuspate, prong, mesh, ring, plug and hard-line reefs. Maxwell finds interesting latitudinal variations in reef orientation, but has little to say about reef features inherited from Pleistocene karst-erosion periods. The treatment of specific reef features is rather unsatisfactory, largely because new information is presented in a shorthand or diagrammatic fashion rather than in detail. This is the case in the treatment of algal-rim variation (pages 102-4) and of reef profiles (page 106). On other topics, such as sand cays, the text is very general and subordinated to photographs, and does not do justice to the work already completed in the Great Barrier Reef area.

The chapter on "Biological Observations" is not up to the standard of the rest of the book. A classification of corals by growth form with mention of a fow genera add. little to our understanding of the complexity of reefs. Some common molluses and echinoderms are illustrated, but this kind of thing is done cqually woll in popular books. There is nothing in this chapter to suggest that our knowledge of reef ecology has advanced materially since the work of Yonge, Stephenson and others forty yoars ago. The term "Lithothamnion Ridge" should by now have disappeared from the literature.

There is in addition much useful background information in the work, particularly on currents and tides, though the discussion on tidal theory is surely out of place. It is a pity that the short list of references was not turned into a proper bibliography: no guide to the literature of the Great Barrier Reef exists, and the seventy references quoted, while including two items from the sixth and several from the sixteenth to eighteenth centuries, omits many important papers by Agassiz, Davis, Fairbridge, Hedloy, Stcors and W. Stephenson. The paper "Sedimentation on Low Isles Reef and its Relation to Coral "rrowth" is given both wrong authorship and wrong citation.

The ideas presented here are fresh and lively, if somewhat speculative. No one concerned with reefs can afford to ignore the book, but neither can they afford to accept its conclusions at their face value. Maxwell, of course, took on an immense task in trying to cover the entire reef-over $200,000 \mathrm{sq} . \mathrm{km}$, much of it largely unexplored; one hopes that he will repeat the exercise on a more restricted scale, and give us chapter and verse for the synthesis attempted here. D. R. STODdarT

\section{MEASURING THE ENVIRONMENT}

\author{
The Measurement of Environmental Factors in Ter- \\ restrial Ecology
}

Edited by R. M. Wadsworth with the assistance of L. C. Chapas, A. J. Rutter, M. E. Solomon and J. Warren Wilson. (British Ecological Society, Symposium No. 8, Reading, March 29-31, 1967.) Pp. $x+314$. (Blackwell Scientific: Oxford and Edinburgh, 1968.) $55 \mathrm{~s}$.

T'HIs is a worthy successor to the earlier symposia of the British Ecological Society; the contributions are carefully chosen to illustrate the theme, and the volume is coherent and well edited throughout. As far as I can see, it will be especially valuable in two ways.

Firstly, it will serve as a cookery book with recipes for anyone who wants to measure environmental factors in terrestrial ecology. There are papers reviewing the measurement of most important factors, four papers on various types of data collecting or logging equipment and one on what to do with punched tape when you have got it. There is also a section devoted to the exhibition of equipment which was an important part of the meeting 